ARTICLE

\title{
Photocatalysis-mediated drug-free sustainable cancer therapy using nanocatalyst
}

\author{
Bin Zhao ${ }^{1,3}$, Yingshuai Wang ${ }^{1,3}$, Xianxian Yao ${ }^{1}$, Danyang Chen ${ }^{1,2}$, Mingjian Fan ${ }^{1}$, Zhaokui Jin (D) ${ }^{1} \&$ \\ Qianjun $\mathrm{He}$ (1) $1,2 \times$
}

Drug therapy unavoidably brings toxic side effects and drug content-limited therapeutic efficacy although many nanocarriers have been developed to improve them to a certain extent. In this work, a concept of drug-free therapeutics is proposed and defined as a therapeutic methodology without the use of traditional toxic drugs, without the consumption of therapeutic agents during treatment but with the inexhaustible therapeutic capability to maximize the benefit of treatment, and a Z-scheme $\mathrm{SnS}_{1.68}-\mathrm{WO}_{2.41}$ nanocatalyst is developed to achieve near infrared (NIR)-photocatalytic generation of oxidative holes and hydrogen molecules for realizing combined hole/hydrogen therapy by the drug-free therapeutic strategy. Without the need of any drug and other therapeutic agent assistance, the nanocatalyst oxidizes/consumes intratumoral over-expressed glutathione (GSH) by holes and simultaneously generates hydrogen molecules in a lasting and controllable way under NIR irradiation. Mechanistically, generated hydrogen molecules and GSH consumption inhibit cancer cell energy and destroy intratumoral redox balance, respectively, to synergistically damage DNA and induce tumor cell apoptosis. High efficacy and biosafety of combined hole/ hydrogen therapy of tumors are achieved by the nanocatalyst. The proposed catalysis-based drug-free therapeutic strategy breaks a pathway to realize high efficacy and low toxicity of cancer treatment.

\footnotetext{
${ }^{1}$ Guangdong Provincial Key Laboratory of Biomedical Measurements and Ultrasound Imaging, National-Regional Key Technology Engineering Laboratory for Medical Ultrasound, Marshall Laboratory of Biomedical Engineering, School of Biomedical Engineering, Health Science Center, Shenzhen University, Shenzhen, Guangdong, China. ${ }^{2}$ Center of Hydrogen Science, Shanghai Jiao Tong University, Shanghai, China. ${ }^{3}$ These authors contributed equally: Bin Zhao, Yingshuai Wang. ${ }^{凶}$ email: nanoflower@126.com
} 
variety of nanomaterials are developed as drug carriers to encapsulate drug molecules and deliver them in a targeted way to the diseased site to enhance drug efficacy and reduce drug side effects ${ }^{1-4}$. As high drug loading capacity as possible is pursued all the way, but is always limited. Drug-free therapeutics, which is defined as a therapeutic methodology without the use of drug, without the consumption of therapeutic agents during treatment but with the inexhaustible therapeutic capability, will maximize the benefit of treatment and is thus worth expecting. Tang et al. developed a calcification method to kill cancer cells by injecting folic acid and $\mathrm{Ca}^{2+}$ into tumor, but these two therapeutic agents were consumed during cancer treatment $^{5}$. Recently, Shi et al. has proposed the concept of nanocatalytic medicine to improve the efficacy of cancer therapy, which can realize drug-free therapy in principle in favor of evading toxic side effects of drug ${ }^{6-10}$. However, most of the developed catalytic nanomedicines have to load toxic drugs and easy-exhaustion therapy-assisted agents. The development of nanocatalytic nanomedicine for drug-free therapy is quite intriguing but still challenging. We here propose to develop drug-free nanocatalysts which can consume intratumoral endogenous substrates to generate therapeutic species for drug-free therapy of cancer.

Electrons and holes generated on the surface of catalyst have reductive and oxidative capabilities, respectively. In theory, electrons with enough high reductive capability $\left(\geq 1.23 \mathrm{eV}\right.$ for $\mathrm{H}^{+}$-to$\mathrm{H}_{2}$ evolution) can be used to reduce endogenous $\mathrm{H}^{+} / \mathrm{CO}_{2} / \mathrm{NO}_{3}{ }^{-}$ into $\mathrm{H}_{2} / \mathrm{CO} / \mathrm{NO}$ for gas therapy ${ }^{11-13}$, while holes with enough high oxidative capability ( $\geq 0.32 \mathrm{eV}$ for GSH-to-GSSG evolution) can be utilized to oxidize glutathione (GSH) into GSSG to destroy the tumor microenvironment for cancer therapy. We here propose a concept of hole therapy, which is defined as a therapeutic methodology of using catalyst-generated holes for disease treatment. The development of wide energy band of catalysts possessing high oxidation and reduction capabilities for hole/gas therapy is vitally important, but still challenging.

The full utilization of NIR light energy at a high proportion (about 50\%) in solar for photocatalytic hydrogen evolution is significant to hydrogen energy but also challenging at present, because NIR-photocatalysts possess narrow energy band width $\left(\leq 1240 / \lambda_{\mathrm{NIR}}, \leq 1.53 \mathrm{eV}\right.$ with $808 \mathrm{~nm}$ NIR light $)$ and too low oxidative capability $\left(\geq 1.23 \mathrm{eV} \text { reduction potential of } \mathrm{H}^{+} / \mathrm{H}_{2}\right)^{14,15}$. As to hydrogen medicine, NIR light as an external stimulus source for photocatalytic hydrogen evolution has obvious advantages over UV/visible light owing to its higher tissue penetrability and lower photo-toxicity ${ }^{16}$. However, the development of photocatalysts for NIR-driven hydrogen evolution for disease treatment is currently facing the similar issues to hydrogen energy. Recently, Sung et al. improved their photo-driven hydrogen-evolving liposome nanoreactor (citrate-UCNP-Au-Chla@liposome) by encapsulating upconversion nanoparticle (UCNP) as NIR-to-visible transducer to realize NIR-photocatalytic production of hydrogen for antiinflammation ${ }^{17-19}$. However, the content of encapsulated sacrificial agent citrate $(6.0 \mathrm{wt} \%)$ is limited and the NIR-to-visible conversion efficiency of UCNP is poor, restricting the amount and efficiency of hydrogen evolution. Here, we hypothesize that the utilization of endogenous reductive substrates such as intratumoral over-expressed GSH $(0.32 \mathrm{eV}$ oxidation potential of GSH/ GSSG) as sacrificial agent could realize long-lasting hydrogen production and drug-free therapy. Moreover, we propose to construct the Z-scheme structure with highly oxidative (low valence band) plasmatic nanodots and NIR-activable (narrow band gap) semiconductor to realize NIR-driven hot electrons injection and high-efficiency NIR-photocatalytic evolution of hydrogen molecules and GSH-oxidizing holes for combined hole/ hydrogen therapy of cancer (Fig. 1).
As to the single-phase nanocrystal catalyst, NIR adsorption edge means narrow band gap $(<1.53 \mathrm{eV}$ for $808 \mathrm{~nm}$ light), slight oxidation at the same time of hydrogen generation, and easy recombination of separated electrons and holes. As to the Januslike Z-scheme structure of nanocrystals such as $\mathrm{MnS}-\mathrm{Cu}_{7} \mathrm{~S}_{4}$ generally constructed by the ion-exchange approach, well-defined interfaces and well-exposed surfaces on both semiconductors favor efficient interfacial charge transfer and reduction/oxidation half-reactions ${ }^{20}$, but the candidate of catalytic materials is limited and the realization of NIR-photocatalytic hydrogen generation is challenging. In comparison, the Z-scheme structure could be constructed facilely by heterogeneous growth without limitation of the choice of catalytic materials ${ }^{21}$. In this work, the screening of two NIR-sensitive catalysts, $\mathrm{SnS}_{1.68}$ nanoplates with a high reductive potential and $\mathrm{WO}_{2.41}$ nanodots with high oxidative potential, for construction of the Z-scheme structure aimed for efficient hydrogen generation and GSH depletion for combined hydrogen/hole therapy. On the one hand, $\mathrm{WO}_{2.41}$ nanodots have an oxygen defect-induced localized surface plasmon resonance effect with strong NIR adsorption as well as a high oxidative potential in favor of GSH oxidation. On the other hand, $\mathrm{SnS}_{1.68}$ nanoplates possess a sulfur-deficient structure, leading to a narrow band gap $(1.49 \mathrm{eV})$ and a NIR absorption edge $(832 \mathrm{~nm})$, in favor of NIR-photocatalytic hydrogen generation. The heterogeneous growth of $\mathrm{WO}_{2.41}$ nanodots on the surface of $\mathrm{SnS}_{1.68}$ nanoplates by a one-pot method enabled NIR-driven hot electrons injection into conjugated $\mathrm{SnS}_{1.68}$ nanoplates, enhancing NIR-photocatalytic reduction for hydrogen generation. Therefore, we chose the materials system of the $\mathrm{Z}$-scheme $\mathrm{SnS}_{1.68}-\mathrm{WO}_{2.41}$ nanocatalyst to realize efficient NIR-driven hydrogen generation and $\mathrm{GSH}$ depletion.

In this work, we proposed a strategy of photocatalysis-mediated drug-free therapeutics, and developed a kind of Z-scheme NIRphotocatalyst by in situ conjugate $\mathrm{WO}_{3-\mathrm{x}}$ nanodots onto $\mathrm{SnS}_{2-\mathrm{y}}$ nanoplates. The NIR-excitated surface plasmatic resonance of $\mathrm{WO}_{3-\mathrm{x}}$ injected hot electrons into $\mathrm{SnS}_{2-\mathrm{y}}$ for NIR-controlled hydrogen evolution and synchronous GSH oxidation by holes (Supplementary Fig. 1). The simultaneous generation of hydrogen molecules and holes enabled hydrogen therapy and hole therapy, respectively, which inhibited cellular energy metabolism and destroyed cellular anti-oxidation defense system (ADS) by GSH decrease and subsequent ROS increase, synergistically inducing the apoptosis of cancer cells (Fig. 1).

\section{Results and discussion}

$\mathrm{SnS}_{2}$ nanoplates with a stoichiometric proportion of $\mathrm{Sn}: \mathrm{S}=1: 2$ were prepared by a solvothermal method, and used as a control. $\mathrm{WO}_{2.41}$ nanodots heterogeneously grew on the surface of $\mathrm{SnS}_{2}$ nanoplates by the solvothermal method, and meanwhile, a part of sulfur was deprived by trimethylamine N-oxide (TMAO) during the oxidation of tungsten, leading to partial lack of sulfur and oxygen for $\mathrm{SnS}_{1.68}-\mathrm{WO}_{2.41}$. Through electrical microscopy observation, both obtained $\mathrm{SnS}_{2}$ and $\mathrm{SnS}_{1.68}-\mathrm{WO}_{2.41}$ exhibited a kind of hexagonal plate-like morphology (Fig. 2a-c and Supplementary Fig. 2) as well as uniform size of about $100 \mathrm{~nm}$ in diameter in favor of cellular uptake. Elementary mapping and highresolution TEM results suggested that there were small nanodots of tungsten oxide (at a $2.5 \%$ molar ratio of $\mathrm{W}$ to Sn, Supplementary Fig. 3) evenly dispersed on the surface of tin sulfide (Fig. 2c and Supplementary Fig. 2e) in favor of localized surface plasmon resonance (LSPR), which could be the reason that the surface of $\mathrm{SnS}_{1.68}-\mathrm{WO}_{2.41}$ nanoplates was rough and porous (Fig. 2a, b and Supplementary Fig. 2d). XPS patterns further indicated that the valence state of $\mathrm{Sn}$ in obtained $\mathrm{SnS}_{2}$ nanoplates was only $4+$, while that in $\mathrm{SnS}_{1.68}-\mathrm{WO}_{2.41}$ nanoplates included 


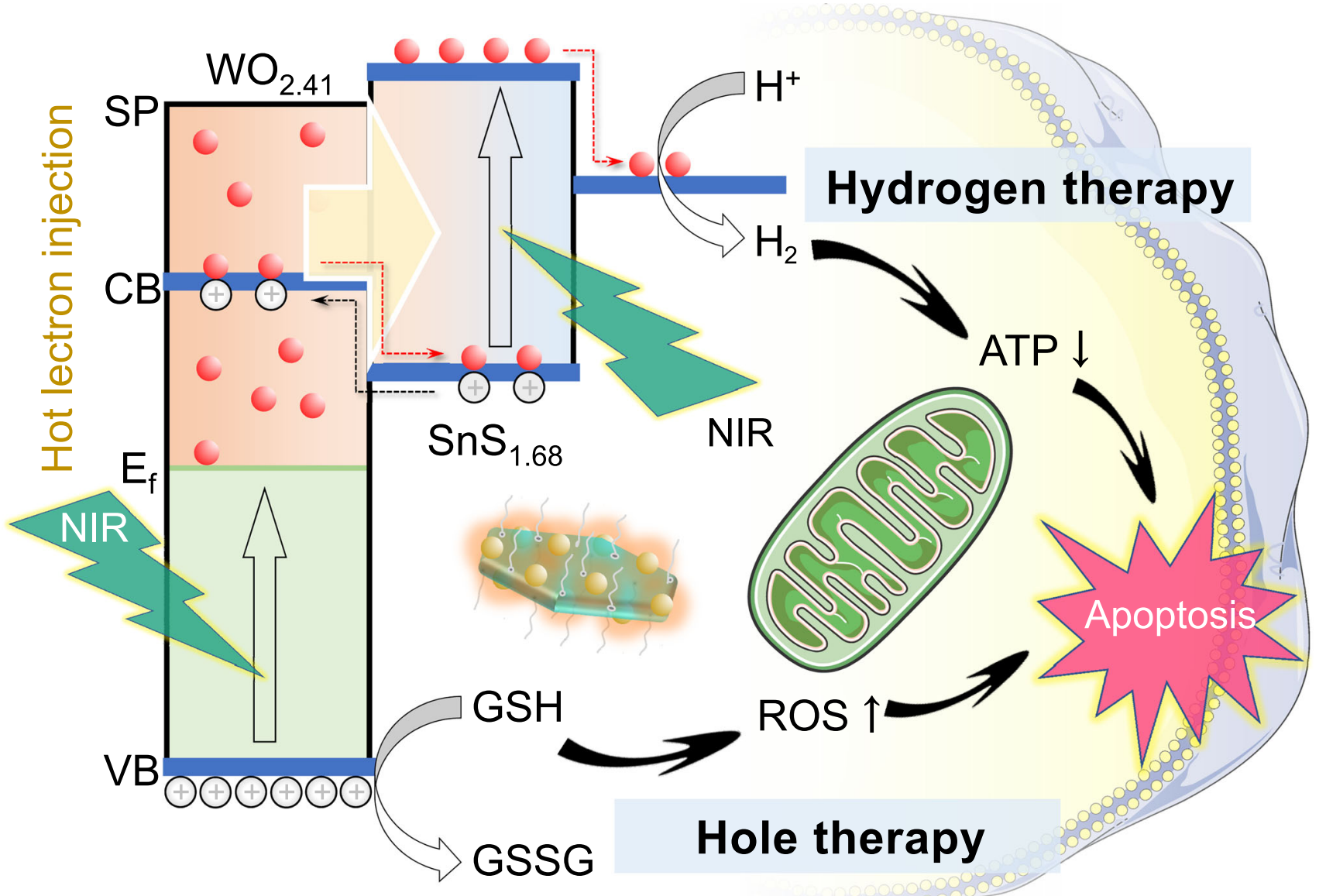

Fig. 1 Schematic illustration of combined hole/hydrogen therapy strategy and mechanisms with the NIR-activable Z-scheme SnS $_{1.68}-W_{2.41}$ nanocatalyst. Several main advances are achieved. (1) Advanced strategy of photocatalysis-mediated drug-free therapeutics is proposed. (2) Advanced $\mathrm{Z}$-scheme $\mathrm{SnS}_{1.68}-\mathrm{WO}_{2.41}$ nanocatalyst is facilely constructed to achieve NIR-triggered efficient generation of highly oxidative holes and hydrogen molecules. (3) Advanced concept and mechanisms for combined hole/hydrogen therapy are proposed and uncovered. (4) Advanced therapeutic performances with drug-free and controllable generation of hydrogen and consumption of intratumoral over-expressed GSH are achieved by the nanocatalyst, realizing high biosafety and high efficacy of drug-free therapy.

$4+$ and $2+$ (Fig. 2d). The ratio of various $S n$ valence states in $\mathrm{SnS}_{1.68}-\mathrm{WO}_{2.41}$ was measured to be $\mathrm{Sn}^{4+}: \mathrm{Sn}^{2+}=0.681: 0.319$, determining the non-stoichiometric ratio of $\mathrm{Sn}: \mathrm{S}=1: 1.68$. Such a sulfur-deficient structure of $\mathrm{SnS}_{1.68}$ led to the slight change in the crystal lattice of $\mathrm{SnS}_{2}$ (Supplementary Fig. 4b). Invisible XRD peaks of tungsten oxide in $\mathrm{SnS}_{1.68}-\mathrm{WO}_{2.41}$ nanoplates (Supplementary Fig. 4a) could result from its small particle size and low content. But FTIR results clearly indicated the composition of $\mathrm{SnS}_{1.68}-\mathrm{WO}_{2.41}$ (Supplementary Fig. 5) in accordance with the above elementary mapping results (Fig. 2c). XPS patterns further confirmed that there were three valence states of tungsten in $\mathrm{SnS}_{1.68}-\mathrm{WO}_{2.41}$ at the ratio of $\mathrm{W}^{6+}: \mathrm{W}^{5+}: \mathrm{W}^{4+}=0.307: 0.216: 0.477$ (Fig. 2e), determining the non-stoichiometric ratio of $\mathrm{W}: \mathrm{O}=$ $1: 2.41$. So many oxygen vacancies in $\mathrm{SnS}_{1.68}-\mathrm{WO}_{2.41}$ nanoplates would greatly favor the enhancement of LSPR ${ }^{22-24}$. In addition, $\mathrm{SnS}_{1.68}-\mathrm{WO}_{2.41}$ nanoplates were conjugated with trithiolterminated poly-(methacrylic acid) (PTMP-PMAA) by a coordination method to enhance their aqueous dispersion ${ }^{25}$. From DLS data in Supplementary Fig. 6, PTMP-PMAA-modified $\mathrm{SnS}_{1.68}-\mathrm{WO}_{2.41}$ nanoplates exhibited good dispersion in water and uniform particle size of about $150 \mathrm{~nm}$ in favor of passive tumor-targeted delivery. Additionally, the chemical stability of $\mathrm{SnS}_{1.68}-\mathrm{WO}_{2.41}$ nanoplates in the $\mathrm{pH} 7.4$ PBS was investigated. From Supplementary Fig. 7, after immersion in the PBS for 7 days, the morphology and adsorption property of $\mathrm{SnS}_{1.68}-\mathrm{WO}_{2.41}$ nanoplates were well maintained, and almost no free $\mathrm{Sn}$ and $\mathrm{W}$ ions can be detected by ICP, suggesting that $\mathrm{SnS}_{1.68}-\mathrm{WO}_{2.41}$ nanoplates were stable enough for therapy.

Photoelectric behaviors and NIR-photocatalytic performances. From Fig. 3a, $\mathrm{WO}_{2.41}$ exhibited a strong LSPR absorption in the range of visible-to-infrared. In addition, $\mathrm{SnS}_{2}$ exhibited a broad UV-visible-NIR absorption and implied a narrow band gap. The mixture structure of $\mathrm{SnS}_{1.68}-\mathrm{WO}_{2.41}$ integrated NIR-absorption behaviors of $\mathrm{WO}_{2.41}$ and $\mathrm{SnS}_{2}$, creating necessary conditions for NIR-photocatalysis. Moreover, the oxygen-deficient structure of $\mathrm{SnS}_{1.68}-\mathrm{WO}_{2.41}$ could enhance LSPR, which will greatly favor the generation of hot electrons on its surface as expected ${ }^{26-29}$. From Fig. $3 \mathrm{~b}$, band gaps of $\mathrm{SnS}_{1.68}$ and $\mathrm{WO}_{2.41}$ within $\mathrm{SnS}_{1.68}-\mathrm{WO}_{2.41}$ were measured to be about $1.49 \mathrm{eV}$ and $2.43 \mathrm{eV}$, respectively. So narrow band gap of $\mathrm{SnS}_{1.68}$ enabled NIR-photoelectric conversion at $\leq 832 \mathrm{~nm}$, and can also provide an enough high reduction potential for $\mathrm{H}^{+} / \mathrm{H}_{2}$ evolution $(1.23 \mathrm{eV})$. Furthermore, NIRphotocurrent measurement with $808 \mathrm{~nm}$ NIR laser indicated that the NIR-photocurrent onset potential ( $\left.\mathrm{V}_{\text {onset }}\right)$ of $\mathrm{SnS}_{1.68}-\mathrm{WO}_{2.41}$ was as low as $0.57 \mathrm{~V}$ (Fig. 3c). By comparison, the NIRphotocurrent $\mathrm{V}_{\text {onset }}$ of $\mathrm{SnS}_{2}$ was much higher $(0.9 \mathrm{~V})$, where the NIR-photocurrent of $\mathrm{SnS}_{1.68}-\mathrm{WO}_{2.41}$ achieved the maximum $\left(0.417 \mathrm{~mA} / \mathrm{cm}^{2}\right)$. It suggested that large amounts of hot electrons 

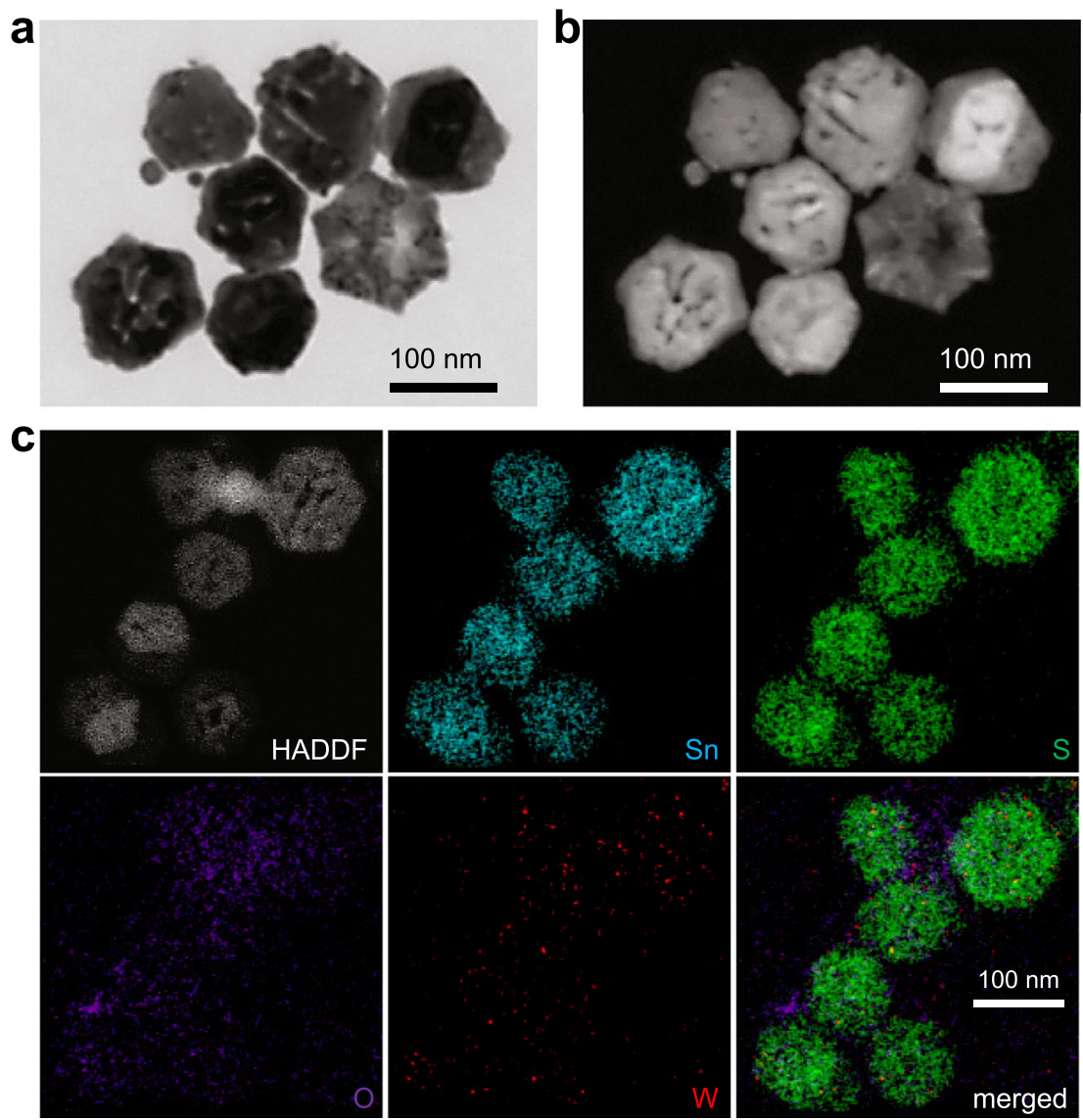
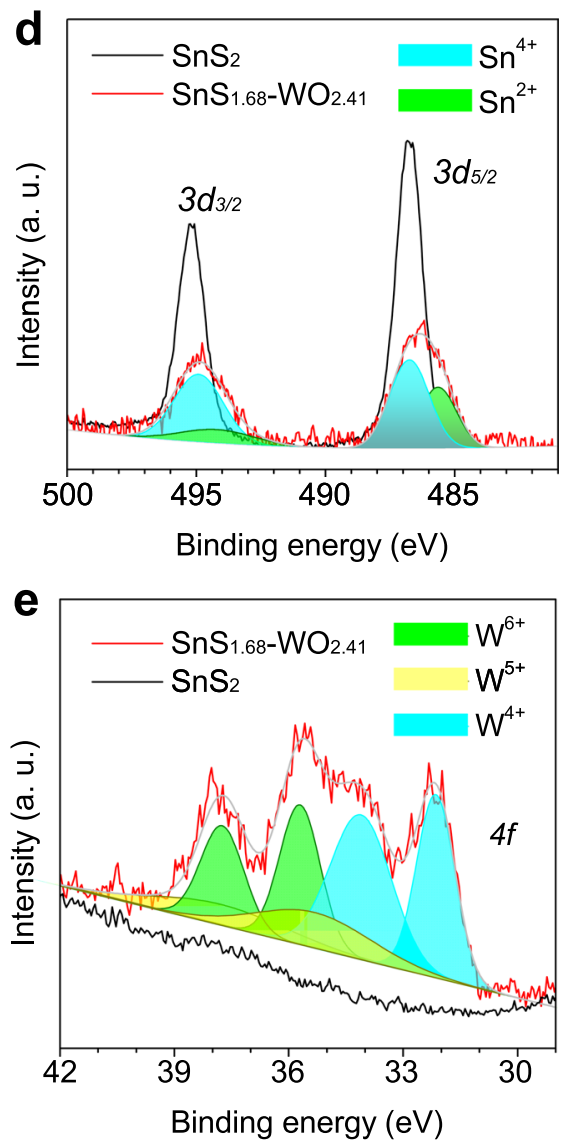

Fig. $\mathbf{2}$ Morphology, composition, and size characterization of the $\mathbf{S n S}_{\mathbf{1 . 6 8}}-\mathbf{W O}_{\mathbf{2 . 4 1}}$ nanocatalyst. SEM (a) and corresponding STEM (b) images, HADDF image and corresponding elementary mapping (c), and XPS patterns (d, e) of the $\mathrm{SnS}_{1.68}-\mathrm{WO}_{2.41}$ nanocatalyst. The experiments were repeated three times independently with similar results.

were easily yielded by $\mathrm{WO}_{2.41}$ on the surface of $\mathrm{SnS}_{1.68}-\mathrm{WO}_{2.41}$ under irradiation of $808 \mathrm{~nm}$ NIR laser owing to its LSPR effect, and then transferred and injected into $\mathrm{SnS}_{1.68}$ by a Z-scheme pathway, as demonstrated by the "Z" photocurrent curve in Fig. 3c. It could be found that both $\mathrm{SnS}_{1.68}$ and $\mathrm{WO}_{2.41}$ within the Z-scheme structure was photoelectrically sensitive to NIR light, greatly favoring the NIR-triggered generation and separation of electrons and holes ${ }^{30,31}$. According to the above-mentioned conclusion, we illustrated the Z-scheme photoelectric structure of the $\mathrm{SnS}_{1.68}-\mathrm{WO}_{2.41}$ nanocatalyst and its mechanism for NIRphotocatalytic hydrogen generation and GSH consumption in Fig. 3d. Additionally, more details for NIR-photocatalytic route were demonstrated in Supplementary Fig. 1. Under NIR excitation, holes $\left(\mathrm{h}^{+}\right)$and electrons $\left(\mathrm{e}^{-}\right)$were generated and separated on the surface of $\mathrm{WO}_{2.41}$ nanodots and $\mathrm{SnS}_{1.68}$ nanoplates, respectively. Holes on the surface of $\mathrm{WO}_{2.41}$ nanodots oxidized GSH into GSSG and generated $\mathrm{H}^{+}$simultaneously. $\mathrm{H}^{+}$transferred from $\mathrm{WO}_{2.41}$ nanodots to $\mathrm{SnS}_{1.68}$ nanoplates, and then was reduced by $\mathrm{e}^{-}$into $\mathrm{H}_{2}$. In a word, GSH became into GSSG and $\mathrm{H}_{2}$ under the NIR-triggered photocatalysis of $\mathrm{SnS}_{1.68}-\mathrm{WO}_{2.41}$.

Furthermore, we checked the NIR-photocatalytic capability of the $\mathrm{SnS}_{1.68}-\mathrm{WO}_{2.41}$ nanocatalyst for hydrogen generation and GSH consumption. Noticeably, a hydrogen electrode was used to monitor the hydrogen generation process of the $\mathrm{SnS}_{1.68}-\mathrm{WO}_{2.41}$ nanocatalyst in real time, where catalyst-free detection solution was separated from NIR-illustrated nanocatalyst solution by a piece of filter membrane (molecular weight cut-off of 3000 Dalton) in order to avoid the effect of photoelectrons on the surface of nanoparticles on the electrode. From Fig. 3e, the $\mathrm{SnS}_{1.68}-\mathrm{WO}_{2.41}$ nanocatalyst can indeed generate hydrogen gas under irradiation of $808 \mathrm{~nm}$ laser, and the hydrogen generation rate depended on NIR laser power density, as higher power density caused faster hydrogen evolution. Moreover, hydrogen generation was highly controllable and repeatable by switching on/off NIR laser, which enabled on-demand hydrogen therapy. When NIR irradiation was switched off, hydrogen concentration went down a little bit owing to low solubility and density-induced hydrogen gas escape from the solution. Furthermore, GSH concentration was also monitored by an Ellmann probe $\left(5,5^{\prime}\right.$ dithiobis-(2-nitrobenzoic acid), DTNB). It was found from Fig. $3 \mathrm{f}$ that GSH consumption was dependent on NIR irradiation. No NIR irradiation almost did not cause GSH consumption, while higher NIR irradiation resulted in more GSH consumption, owing to GSH oxidation by photo-generated holes on the $\mathrm{SnS}_{1.68}-\mathrm{WO}_{2.41}$ nanocatalyst rather than by the nanocatalyst itself, enabling hole therapy. The GSH consumption seems to have a linear relationship with irradiation time, indicating the nanocatalyst can steadily oxidize GSH for generating hydrogen molecule with high cycle stability of NIR-photocatalysis. It is worth noting that such a drug-free therapy method is sustainable and repeatable without restrictions, empowering any extent of therapy for optimal outcomes.

In vitro hole/hydrogen therapy efficacies and mechanisms. Cellular uptake behavior of the $\mathrm{SnS}_{1.68}-\mathrm{WO}_{2.41}$ nanocatalyst was investigated first. From Fig. 4a, the $\mathrm{SnS}_{1.68}-\mathrm{WO}_{2.41}$ nanocatalysts were largely endocytosed through the lysosomal pathway by HeLa cells after $4 \mathrm{~h}$ incubation, owing to their small particle size in favor of cellular uptake. Effective cellular uptake of nanocatalysts would 

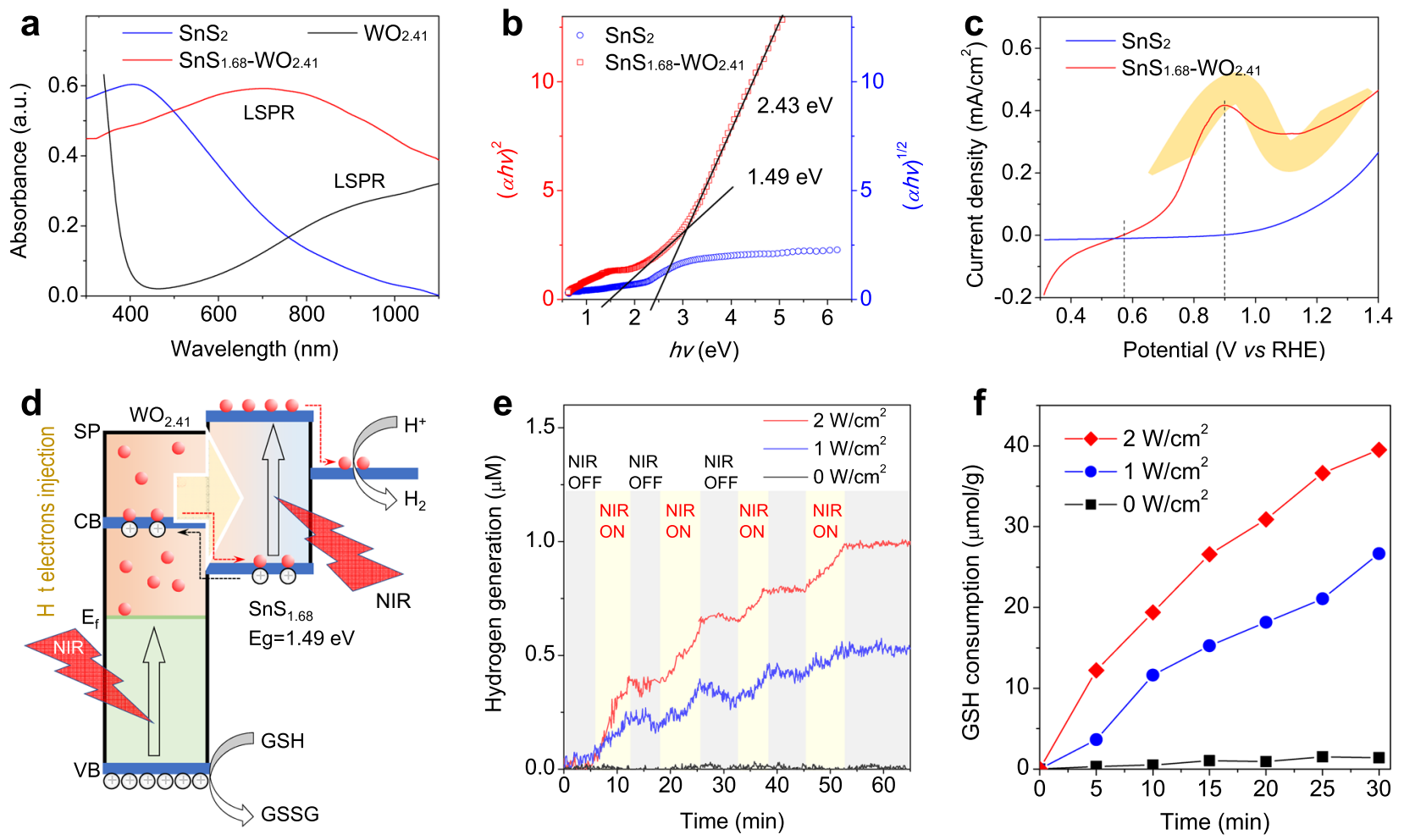

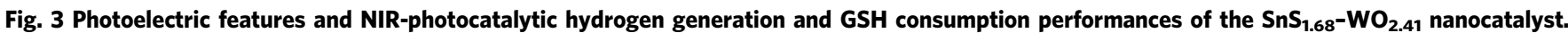
UV-VIS-NIR adsorption spectra (a), the plots of $(\alpha h \nu)^{1 / 2}$ and $(\alpha h \nu)^{2}$ versus energy (hv) for band gaps of $\mathrm{SnS}_{2}$ and $\mathrm{SnS}_{1.68}-\mathrm{WO}_{2.41}(\mathbf{b})$, photocurrent density-voltage (vs. RHE) curves of $\mathrm{SnS}_{2}$ and $\mathrm{SnS}_{1.68}-\mathrm{WO}_{2.41}$ under irradiation of $808 \mathrm{~nm}$ laser (c), the schematic illustration of the mechanism for NIRphotocatalytic hydrogen generation and GSH consumption (d), NIR-photocatalytic hydrogen generation behavior of the $\mathrm{SnS}_{1.68}-\mathrm{WO}_{2.41}$ nanocatalyst in the aqueous solution of GSH $(10 \mu \mathrm{M})$ under irradiation of $808 \mathrm{~nm}$ laser at various power densities (e), NIR-photocatalytic GSH consumption behavior of the $\mathrm{SnS}_{1.68}-\mathrm{WO}_{2.41}$ nanocatalyst under irradiation of $808 \mathrm{~nm}$ laser at various power densities (f). The experiments for figures $\mathbf{a}, \mathbf{e}, \mathbf{f}$ was repeated three times independently with similar results.

be favorable for cancer therapy. Furthermore, the cytotoxicity of nanocatalysts was investigated with $\mathrm{SnS}_{2}$ nanoplates and $\mathrm{WO}_{2.41}$ nanodots as two controls that cannot oxidize GSH and generate hydrogen molecules under NIR irradiation because of unqualified energy band structures. From Fig. $4 \mathrm{~b}$ and Supplementary Fig. 8c, the control groups of $\mathrm{SnS}_{2}$ nanoplates and $\mathrm{WO}_{2.41}$ nanodots did not affect the viability of $4 \mathrm{~T} 1$ and HeLa cells in the absence and presence of NIR irradiation. Even after incubation $48 \mathrm{~h}$, no visible dark cytotoxicities of $\mathrm{SnS}_{2}, \mathrm{WO}_{2.41}$, and $\mathrm{SnS}_{1.68}-\mathrm{WO}_{2.41}$ within a wide particle concentration range of $37.5-600 \mu \mathrm{g} / \mathrm{mL}$ were exhibited (Supplementary Fig. 8ab), indicating high cytocompatibility of nanocatalysts. By comparison, $\mathrm{SnS}_{1.68}-\mathrm{WO}_{2.41}$ nanoplates plus NIR irradiation exhibited obvious cytotoxicity to $4 \mathrm{~T} 1$ and HeLa cells with IC50 $=32.6 \mu \mathrm{g} / \mathrm{mL}$ at $0.2 \mathrm{~W} / \mathrm{cm}^{2}$, and IC50 $=17.1 \mu \mathrm{g} / \mathrm{mL}$ at $0.5 \mathrm{~W} / \mathrm{cm}^{2}$ for 4 T1 cells $\left(\mathrm{IC} 50=52.3 \mu \mathrm{g} / \mathrm{mL}\right.$ at $0.2 \mathrm{~W} / \mathrm{cm}^{2}$, and IC $50=20.1 \mu \mathrm{g} / \mathrm{mL}$ at $0.5 \mathrm{~W} / \mathrm{cm}^{2}$ for HeLa cells) (Fig. $4 \mathrm{~b}$ and Supplementary Fig. 8c), owing to the occurrence of NIRphotocatalysis. In order to check the effect of individual hole or hydrogen, ultraviolet (UV) light was used instead of NIR to irradiate $\mathrm{SnS}_{2}+250 \mu \mathrm{M} L$-ascorbic acid (AA) or $\mathrm{WO}_{2.41}+250 \mu \mathrm{M}$ $\mathrm{Na}_{2} \mathrm{~S}_{4} \mathrm{O}_{6}$ to generate only hydrogen molecules or holes, respectively. From Supplementary Fig. 9b, UV irradiation of $\mathrm{SnS}_{2}$ or $\mathrm{WO}_{2.41}$ can kill $4 \mathrm{~T} 1$ cells mildly in a power density-/concentrationdependent way, suggesting that photo-generated holes and hydrogen molecules have anti-cancer effects, which are here defined as hole therapy and hydrogen therapy. By comparison, combined hole/hydrogen therapy groups of $\mathrm{SnS}_{1.68}-\mathrm{WO}_{2.41}$ plus UV irradiation demonstrated remarkably higher cytotoxicity at the same particle concentration and power density. Enhanced anticancer efficacies were attributed to the effective combination of hole therapy and hydrogen therapy, demonstrating the advantages of drug-free therapy in therapy efficacy.

It has well proved that the main target of hydrogen molecule is mitochondrion and thus hydrogen gas can induce cancer apoptosis by adjusting cellular energy metabolism through mitochondria ${ }^{32,33}$, while GSH depletion can do damage to the ADS of cancer because intratumoral over-expressed GSH has high reduction capability and play an essential role in maintaining intratumoral redox balance ${ }^{34-38}$. Therefore, we investigated the effect of the $\mathrm{SnS}_{1.68}-\mathrm{WO}_{2.41}$ nanocatalyst on both intracellular levels of ATP and ROS and the functions of mitochondria and DNA in the presence and absence of NIR irradiation in order to uncover the mechanism of hole/hydrogen therapy. First, catalytic GSH oxidation (Supplementary Fig. 10a) and hydrogen evolution (Supplementary Fig. 10b) were further confirmed in the model of 4T1 cells in accordance to the above-mentioned results in the simulated fluid (Fig. 3ef), which was responsible for abovementioned hole/hydrogen therapy outcomes (Fig. 4b). Furthermore, intracellular ROS monitoring results from Fig. 4c indicated that $10 \mathrm{~min}$ NIR irradiation to $\mathrm{SnS}_{1.68}-\mathrm{WO}_{2.41}$ nanocatalysttreated $4 \mathrm{~T} 1$ cells quickly caused the visible increase of intracellular ROS level in a power density-/concentration-dependent way, but no NIR irradiation did not affect intracellular ROS level obviously. It is worth noting that intracellular ROS level persistently increased (up to two folds within $1.5 \mathrm{~h}$ at $0.5 \mathrm{~W} / \mathrm{cm}^{2}$ at $100 \mu \mathrm{g} / \mathrm{mL}$ ) after stopping NIR irradiation, indicating that the damage of GSH oxidation to the ADS can be gradually amplified and then persisted for a long term $(>4.5 \mathrm{~h}$, Fig. $4 \mathrm{c})$. Such a remarkable and irreducible enhancement of intracellular ROS level led to visible DNA damage (Fig. $4 \mathrm{f}$ and Supplementary 


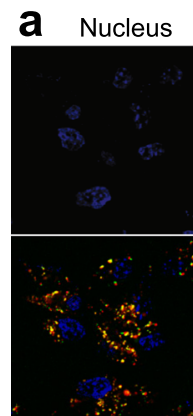

RGB merged
Lysosome $\mathrm{SnS}_{168}-\mathrm{WO}_{241}$

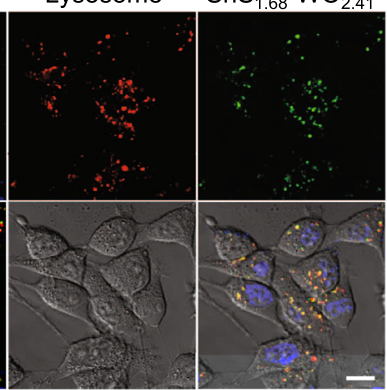

Bright Field All merged

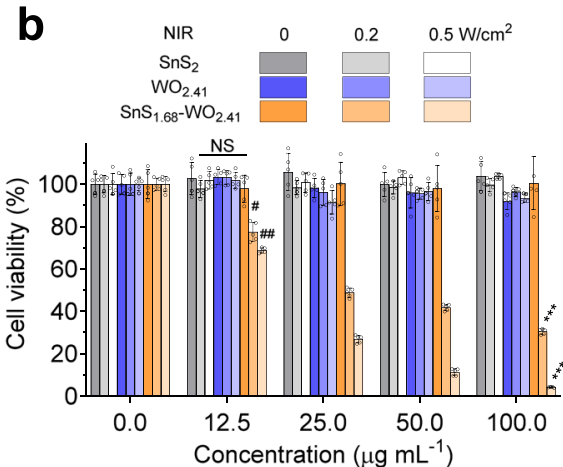

Concentration $\left(\mu \mathrm{g} \mathrm{mL}^{-1}\right)$
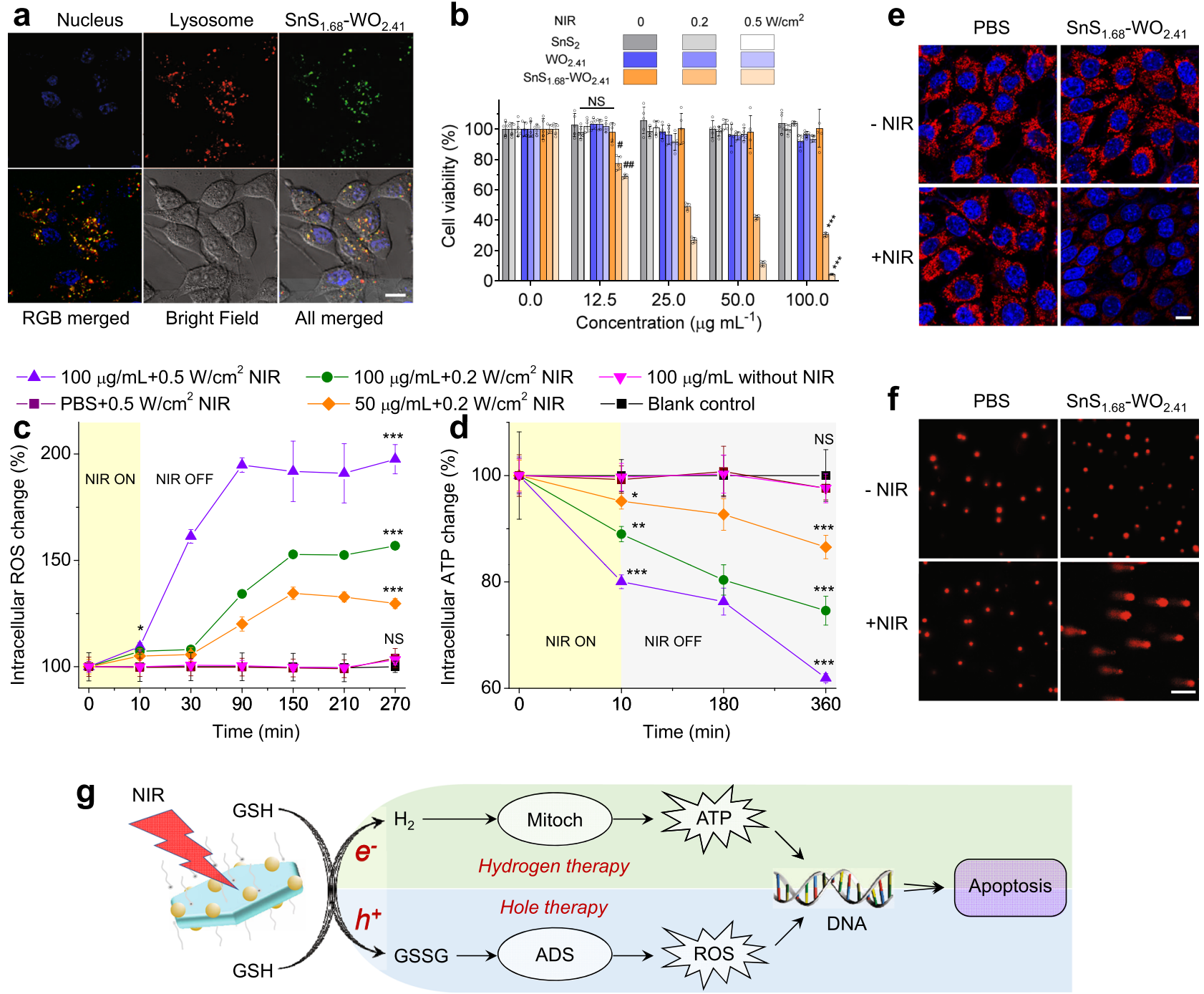

Fig. 4 Combined hole/hydrogen therapy performances and mechanisms of the $\mathbf{S n S}_{\mathbf{1 . 6 8}}-\mathbf{W O}_{\mathbf{2 . 4 1}}$ nanocatalyst. The cellular uptake behavior of the $\mathrm{SnS}_{1.68}-\mathrm{WO}_{2.41}$ nanocatalyst after incubation for $4 \mathrm{~h}(\mathbf{a})$, the cytotoxicity $(n=5$ biologically independent cells) of the nanocatalyst in the presence/absence of NIR irradiation ( $808 \mathrm{~nm}, 0.2$ or $0.5 \mathrm{~W} / \mathrm{cm}^{2}, 10 \mathrm{~min}$ ) against 4 T1 cells $(\mathbf{b})$, the intracellular ATP (c) and ROS (d) monitoring ( $n=6$ biologically independent samples) in $\mathrm{SnS}_{1.68}-\mathrm{WO}_{2.41}$-treated $4 \mathrm{T1}$ cells in the presence/absence of NIR irradiation ( $808 \mathrm{~nm}, 0.2 \mathrm{or} 0.5 \mathrm{~W} / \mathrm{cm}^{2}$, $10 \mathrm{~min}$ ), the effect of $\mathrm{SnS}_{1.68}-\mathrm{WO}_{2.41}+$ NIR treatment on the mitochondria (The experiments were repeated three times independently with similar results) (e) and DNA (f) of $4 \mathrm{~T} 1$ cells, and the proposed mechanism for combined hole/hydrogen therapy based on the $\mathrm{SnS}_{1.68}-\mathrm{WO}_{2.41}$ nanocatalyst ( $\mathbf{g}$ ). $P$ values were calculated by the two-tailed Student's $t$-test $\left({ }^{\#} P=0.000253,{ }^{\# \#} P=0.000007,{ }^{\star} P=0.001356,{ }^{\star \star} P=0.000006,{ }^{\star \star \star} P<0.000001 ;\right.$ NS, no significant difference). Scale bars, $10 \mu \mathrm{m}(\mathbf{a}, \mathbf{e}), 100 \mu \mathrm{m}(\mathbf{f})$. Data are presented as mean values \pm SD.

Fig. 11), being accountable for hole therapy. On the other hand, NIR-photocatalytically generated hydrogen gas severely impaired the mitochondria of $4 \mathrm{~T} 1$ cells (Fig. 4e and Supplementary Fig. 12), and thus caused the remarkable reduction in cellular energy level (Fig. 4d). Moreover, the response of intracellular ATP to hydrogen molecules was synchronous with the response of intracellular ROS to GSH oxidation, and even more persistent in favor of sustained proapoptosis. The hydrogen-mediated decrease of cellular energy level can not only directly induce the apoptosis of cancer cells but also impede the repairing of DNA damage ${ }^{38}$, and therefore synergistically enhance the effect of hole therapy. By comparison, $\mathrm{SnS}_{2}$ nanoplates did not affect intracellular levels of ROS and ATP despite concentration and NIR irradiation (Supplementary Fig. 13), probably owing to their good cytocompatibility and impossible NIR-photocatalysis. Based on above conclusion, we proposed the mechanism of combined hole/hydrogen therapy based on the $\mathrm{SnS}_{1.68}-\mathrm{WO}_{2.41}$ nanocatalyst, as illustrated in Fig. 4g.
In vivo hole/hydrogen therapy outcomes. In vivo tumortargeted hole/hydrogen therapy efficacies of the $\mathrm{SnS}_{1.68}-\mathrm{WO}_{2.41}$ nanocatalyst were further investigated using two kinds of tumor mouse models built with murine $4 \mathrm{~T} 1$ breast cancer cells and human HeLa cervical cancer cells. First, from ICP measurement results (Supplementary Fig. 14), the $\mathrm{SnS}_{1.68}-\mathrm{WO}_{2.41}$ nanocatalyst can effectively accumulate in the tumor site with a high accumulation efficiency (about 12\%) and a relative long blood circulation time (about $1 \mathrm{~h}$ ) after intravenous injection in a passive targeting way, owing to small and uniform particle size of nanocatalyst. During the $20 \mathrm{~min}$ NIR irradiation treatment, the temperature of irradiated tumors was monitored in real time by an infrared thermal imaging instrument and was found to always maintain below $40^{\circ} \mathrm{C}$, indicating that photothermal effect of the nanocatalyst was quietly slight. NIR irradiation was operated at day 1 and day 3. After treatment for 22 days, both $4 \mathrm{~T} 1$ and HeLa tumors were effectively inhibited (Fig. 5a, Supplementary 

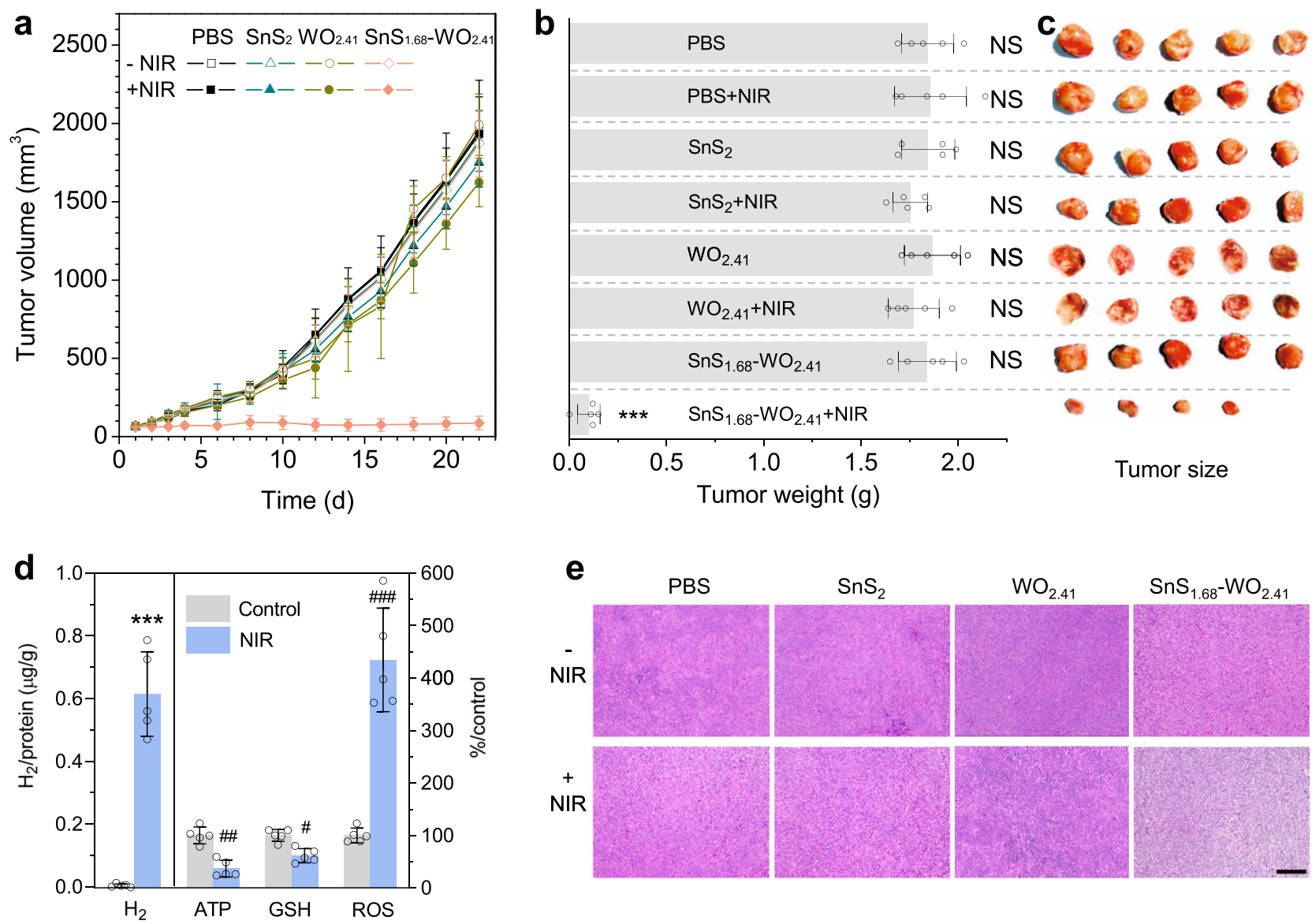

Fig. 5 In vivo combined hole/hydrogen therapy performances of the $\mathbf{S n S}_{\mathbf{1 . 6 8}}-\mathbf{W O}_{\mathbf{2 . 4 1}}$ nanocatalyst. The monitoring of $4 \mathrm{T1}$ tumor volume (a), the weight (b) and size (c) of extracted 4T1 tumors after 22-day treatment ( $n=5$ biologically independent samples), the intratumoral $\mathrm{H}_{2}$, ATP, GSH, and ROS levels (d) before and after NIR irradiation ( $20 \mathrm{~min}, 0.5 \mathrm{~W} / \mathrm{cm}^{2}$ ) on nanocatalyst-treated tumor mice ( $n=5$ biologically independent samples), and the HE stained tumor tissue slices (e). Scale bar, $200 \mu \mathrm{m}$. $P$ values were calculated by the two-tailed Student's $t$-test $(\# P=0.000653, \# \# P=0.00007, \# \# \#=0.000015$, ${ }^{\star \star \star} P<0.000001$; NS, no significant difference). Data are presented as mean values \pm SD.

Fig. 15a), and even one of five $4 \mathrm{~T} 1$ tumors was completely eradicated (Fig. 5b). By comparison, neither the $\mathrm{SnS}_{1.68}-\mathrm{WO}_{2.41}$ nanocatalyst without NIR irradiation nor the $\mathrm{SnS}_{2}$ nanoplates with/without NIR irradiation remarkably affected tumor growth of $4 \mathrm{~T} 1$ tumors (Fig. 5b, c) and HeLa tumors (Supplementary Fig. 15b, c), owing to no generation of hydrogen and hole in these groups.

The proposed-above mechanism for combined hole/hydrogen therapy based on cell experiments (Fig. $4 \mathrm{~g}$ ) was further verified in vivo. After $0.5 \mathrm{~W} / \mathrm{cm}^{2}$ NIR irradiation on tumors for $20 \mathrm{~min}$, intratumoral GSH level sharply declined and hydrogen gas was generated largely (Fig. 5d), indicating intratumoral efficient NIRphotocatalytic hydrogen generation and GSH oxidation by $\mathrm{SnS}_{1.68}-\mathrm{WO}_{2.41}$ in good accordance with in vitro results. Meanwhile, intratumoral ROS and ATP levels intensively increased and decreased (Fig. 5d), respectively, in good consistence with in vitro results. Finally, most of the tumor cells treated with $\mathrm{SnS}_{1.68}-\mathrm{WO}_{2.41}$ plus NIR irradiation died without nuclei (blue, Fig. 5e), implying DNA damage. Therefore, in vivo results suggested that NIRphotocatalytical GSH oxidation caused the increase of intratumoral ROS level and thus damaged the DNA of tumor cells to induce tumor apoptosis, while NIR-photocatalytically generated hydrogen gas inhibited the energy level of tumor cells and consequently prevented from DNA repair to accelerate tumor apoptosis, further confirming the proposed mechanism for combined hole/hydrogen therapy (Fig. 4g).
Furthermore, we investigated the change of tumor microenvironment (TME) after hole/hydrogen therapy to deeply understand its influence. There are a variety of tumorassociated stromal cells, involving inflammatory cells, vascular cells, and fibroblasts, which make important contributions together to TME in support of tumor angiogenesis, proliferation, invasion, metastasis, and therapeutic resistance. Besides, tumor defense systems in TME safeguard the normal running of tumor system from internal and external attacks. Doing damage to TME by destroying tumor defense systems is equally important with directly killing tumor cells, and it has been well recognized that combined therapy for simultaneously damaging TME and killing tumor cells is more efficient than individual therapy, typically immunochemotherapy ${ }^{39}$. After hole/hydrogen therapy, the proliferation of $\mathrm{Ki}^{+} 7^{+}$tumor cells was almost thoroughly suppressed (Fig. 6a); both Caspase-3-positive $\left(\mathrm{Cap}^{+}\right)$and terminal deoxynucleotidyl transferase-mediated deoxyuridine triphosphate nick end labeling-positive $\left(\mathrm{TUNEL}^{+}\right)$cellular apoptosis increased remarkably (Fig. 6b, c); excessive CD $31^{+}$ vasculatures regressed drastically (Fig. 6d); and tumor-associated macrophages $\left(\mathrm{Ibal}^{+}\right.$) were also almost fully eradicated (Fig. 6e), indicating that tumor-induced immunodepression was demilitarized. It could be found that the whole TME was completely altered by hole/hydrogen therapy, which was possibly one of main reasons of good therapy outcomes. By comparison, other control groups did not cause remarkable changes of TME 
a

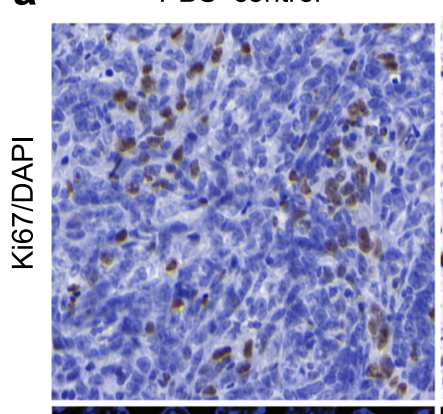

$$
\mathrm{SnS}_{1.68}-\mathrm{WO}_{2.41}+\mathrm{NIR}
$$

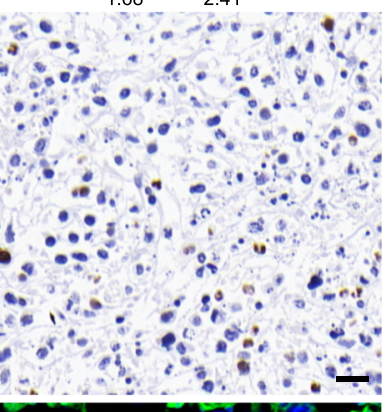

C
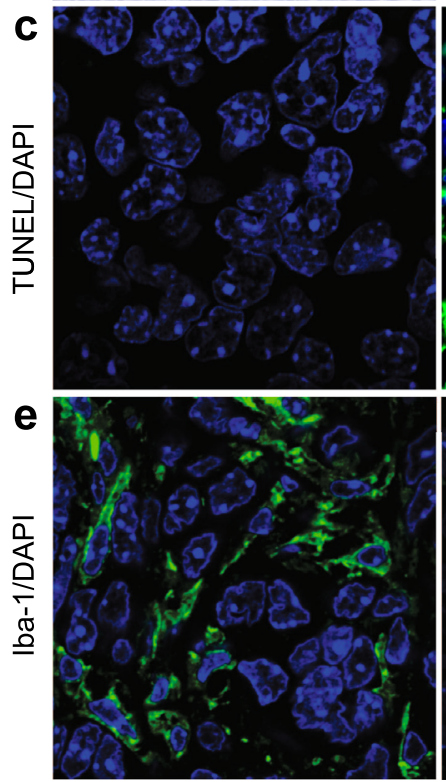
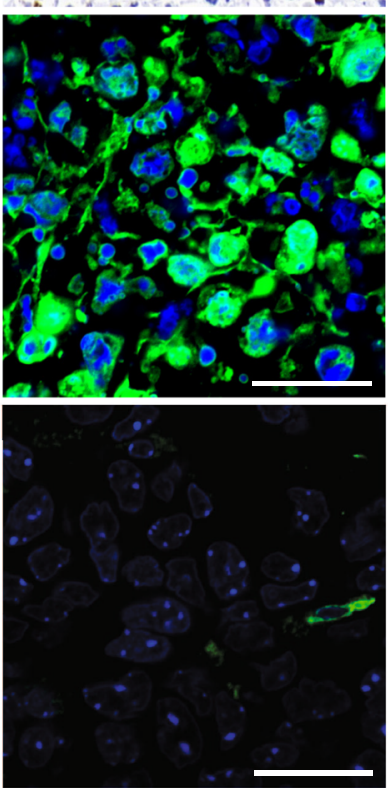

b
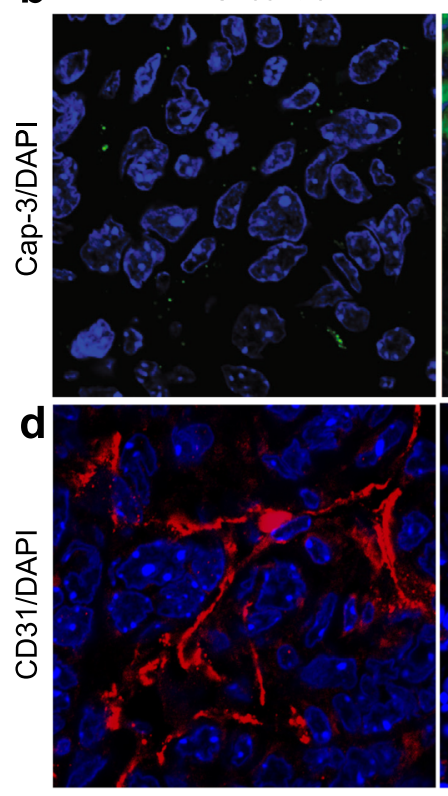

f

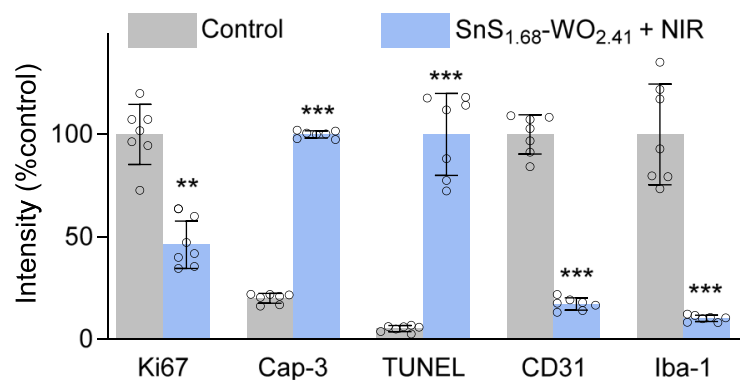

Fig. 6 The change of TME after hole/hydrogen therapy with the $\mathbf{S n S} \mathbf{1 . 6 8}_{\mathbf{8}}-\mathbf{W O}_{\mathbf{2 . 4 1}}$ nanocatalyst. Immunohistochemical analysis of $\mathrm{Ki} 67^{+}$proliferating cells (a), caspase- $3^{+}$apoptotic cells (b), TUNEL ${ }^{+}$apoptotic cells (c), CD31+ tumor vessels (d), and lba1+ tumor-associated macrophages (e) in 4T1 tumors, and corresponding quantification results ( $n=7$ biologically independent samples) (f). All the scale bars, $20 \mu \mathrm{m}$. $P$ values were calculated by the two-tailed Student's $t$-test $\left.{ }^{\star \star} P=0.000006,{ }^{\star \star \star} P<0.000001\right)$. Data are presented as mean values \pm SD.

(Supplementary Fig. 16). By virtue of hole/hydrogen therapy, both GSH depletion and hydrogen regulation upon tumor tissue could spread over the whole of TME, destroy the ADS in TME, and influence all tumor and tumor-associated stromal cells because of high tissue penetration of GSH and hydrogen molecules. Such a special feature of hole/hydrogen therapy is distinctly different from that of general drug therapies because of no drug resistance and no limitation of tissue penetration of nanoparticles, implying underlying clinical values of drug-free therapy.

Moreover, the biosafety of the $\mathrm{SnS}_{1.68}-\mathrm{WO}_{2.41}$ nanocatalyst was elevated by measuring its tissue and blood compatibilities since it distributed in multiple organs after intravenous injection. All treatment groups did not caused distinct body weight change (from Supplementary Figs. 17 to 18) or visible damage to main organs, including heart, liver, spleen, lung, and kidney after treatment for 22 days (from Supplementary Figs. 19 to 20), indicating good tissue compatibility of the $\mathrm{SnS}_{1.68}-\mathrm{WO}_{2.41}$ nanocatalyst. The general haematology parameters (red blood cells, white blood cells, haemoglobin, haematocrit, mean corpuscular haemoglobin, mean corpuscular haemoglobin concentration, and mean corpuscular volume) and standard blood biochemical indexes (alanine transaminase, aspartate transaminase, alkaline phosphatase, blood urea nitrogen, and creatinine) were assayed after intravenous injection of the $\mathrm{SnS}_{1.68}-\mathrm{WO}_{2.41}$ nanocatalyst $(10 \mathrm{mg} / \mathrm{kg})$ for 2 week. From Supplementary Fig. 21 to 22 , there were no statistically significant differences in both haematology parameters and blood biochemical indexes between the $\mathrm{SnS}_{1.68}-\mathrm{WO}_{2.41}$ nanocatalyst and the control group, indicating good blood compatibility and no obvious toxicity to liver and kidney. It is noticeable that no NIR-irradiation did not trigger photocatalytic reactions and consequently did not cause toxicity to normal organs, and there was no toxic side effects of drug because no drug was used, reflecting the incomparable advantages of drug-free therapy in biosafety. Additionally, the toxicity of tungsten as a heavy metal is mainly demonstrated by soluble tungstates rather than by relatively more stable tungsten oxide and metal tungsten ${ }^{40-48}$, and therefore the development of tungsten oxide for biomedical applications is broadly being studies ${ }^{42-48}$ where high biocompatibility with lowest toxic dose of $1000 \mathrm{mg} / \mathrm{kg}$ for oral administration was demonstrated. In this work, we also found that neither $\mathrm{WO}_{3}$ nor $\mathrm{SnS}_{1.68}-\mathrm{WO}_{2.41}$ exhibited obvious cytotoxicity ( $600 \mu \mathrm{g} / \mathrm{mL}$, Supplementary Fig. 8), side effect on intracellular GSH, mitochondria, and DNA (Supplementary Figs. 10-12), mice body weight change, tissue toxicity, and damage to liver/kidney functions $(100 \mathrm{mg} / \mathrm{kg}$ for intravenous injection, Supplementary Figs. 17-22). For future clinical application, both local injection and nanocatalystencapsulating microneedle patch are optional administration routes for treatment of superficial tumors to avoid the risk of potential long-term toxicity of the nanocatalyst to normal tissues.

In summary, we developed the $\mathrm{Z}$-scheme $\mathrm{SnS}_{1.68}-\mathrm{WO}_{2.41}$ nanocatalyst by the one-pot method to realize NIR-photocatalytic generation of holes and hydrogen molecules for combined hole/ 
hydrogen therapy. Large amounts of hot electrons were easily yielded by plasmatic $\mathrm{WO}_{2.41}$ nanodots and injected into NIRsensitive $\mathrm{SnS}_{1.68}$ nanoplate by a Z-scheme pathway, enabling efficient NIR-photocatalysis. The $\mathrm{SnS}_{1.68}-\mathrm{WO}_{2.41}$ nanocatalyst exhibited controlled NIR-photocatalytic hydrogen generation and GSH oxidation in vitro and in vivo, and effectively killed cancer cells and inhibited tumor growth by depressing cancer cell energy metabolism, enhancing intratumoral ROS level and inducing DNA damage. By the drug-free therapy strategy, the nanocatalyst harvested great benefits in the efficacy and biosafety of cancer therapy. Overall, the proposed catalyst-based drug-free therapy is a promising strategy for clinical cancer treatment.

\section{Methods}

Synthesis of $\mathbf{S n S}_{\mathbf{2}}$ nanoplates. $\mathrm{SnCl}_{4} \cdot 5 \mathrm{H}_{2} \mathrm{O}(0.3 \mathrm{mmol})$ and oleylamine $(1.5 \mathrm{~mL})$ was dissolved into anisole $(28 \mathrm{~mL})$ and then the mixture was slowly heated to $70^{\circ} \mathrm{C}$ in oil bath. After stirred for $30 \mathrm{~min}$, the solution became colorless and transparent, and then was cooled down to room temperature. $\mathrm{CS}_{2}(0.75 \mathrm{~mL})$ was added under stirring. After $30 \mathrm{~min}$, the solution turned into transparent yellowish color. The solution was heated to $180^{\circ} \mathrm{C}$ in a polytetrafluoroethylene lined autoclave of $50 \mathrm{~mL}$. After $12 \mathrm{~h}$, the solution was cooled to room temperature, and then as-prepared $\mathrm{SnS}_{2}$ nanoplates were collected by centrifugation and washed twice with anhydrous ethanol $^{49}$

Synthesis and modification of $\mathrm{SnS}_{\mathbf{1 . 6 8}}-\mathbf{W O}_{\mathbf{2 . 4 1}}$ nanoplates. The oleylamine solutions of $\mathrm{SnS}_{2}$ nanoplates $(2 \mathrm{~mL}, 10 \mathrm{mg} / \mathrm{mL})$ and $\mathrm{W}(\mathrm{CO})_{6}(1 \mathrm{~mL}, 5 \mathrm{mg} / \mathrm{mL})$ were mixed with oleylamine $(17 \mathrm{~mL})$. After stirring at $60^{\circ} \mathrm{C}$ for $30 \mathrm{~min}$, the oleylamine solution of trimethylamine $\mathrm{N}$-oxide dihydrate (TMAO, $1 \mathrm{~mL}, 4.75 \mathrm{mg} / \mathrm{mL}$ ) was added into the above solution. After stirred for another $30 \mathrm{~min}$, the solution was quickly heated to $260^{\circ} \mathrm{C}$ under the protection of Ar atmosphere. After $12 \mathrm{~min}$, toluene $(10 \mathrm{~mL})$ was dropwise added into the solution to quickly cool it to room temperature in order to quench the reaction. The as-prepared $\mathrm{SnS}_{1.68}-\mathrm{WO}_{2.41}$ nanoplates were collected by centrifugation, washed three times with the mixture of hexane $(8 \mathrm{~mL})$ and methanol $(12 \mathrm{~mL})$, and dispersed into ethanol for the following use. As a control, $\mathrm{WO}_{2.41}$ nanodots were synthesized by the similar route without the addition of $\mathrm{SnS}_{2}$ nanoplates.

The nanoplates were modified with trithiol-terminated poly-(methacrylic acid) (PTMP-PMAA) by the coordination route. In a typical procedure, the ethanol $(100 \mathrm{~mL})$ solution of methacrylic acid (MAA monomer, $10.888 \mathrm{~g})$, pentaerythritol tetra(3-mercaptopropionate) (PTMP, $1.222 \mathrm{~g}$ ) and azodiisobutyronitrile (AIBN, $0.2 \mathrm{~g}$ ) was refluxed at $75^{\circ} \mathrm{C}$ for $5.5 \mathrm{~h}$ under magnetic stirring and protection of $\mathrm{Ar}$ atmosphere. The solvent ethanol was removed by rotary distillation, and then the viscous product PTMP-PMAA was isolated by precipitation with cold anhydrous ether $\left(4^{\circ} \mathrm{C}\right)$, and then dried under vacuum at $45^{\circ} \mathrm{C}$ for $24 \mathrm{~h}$. The ethanol solution of PTMP-PMAA $(1 \mathrm{~mL}, 10 \mathrm{mg} / \mathrm{mL})$ was slowly dropped into that of nanoplates $(5 \mathrm{mg}, 10 \mathrm{~mL})$ in an ultrasound bath. After sonication for $1 \mathrm{~h}$, the solution was stirred for $24 \mathrm{~h}$. The PTMP-PMAA modified nanoplates were collected by centrifugation and washed three times with ultrapure water to remove excessive PTMP-PMAA.

Characterization of nanoplates. The morphology and size of nanoplates were measured by SEM (APREO, FEI) and TEM (JEM-2100F). Hydrodynamic size of nanoplates was measured on a Malvern Zetasizer Nano ZS90. The composition of nanoplates was determined by Fourier transform infrared spectroscopy (FTIR) on a Thermo-Nicolet Nexus 670 ATR-IR spectrometer. The UV absorption spectra were recorded on a Genesys 10S UV-Vis spectrophotometer. The photocurrent of nanoplates-coated indium tin oxide (ITO) glass was measured on a CHI 660D electrochemical station (Shanghai Chenhua, China) under irradiation of $1 \mathrm{~W} / \mathrm{cm}^{2}$ $808 \mathrm{~nm}$ monochromatic light. During the test, a standard three-electrode device with the ITO glass as the working electrode, the platinum foil as the counter electrode, and the $\mathrm{Ag} / \mathrm{AgCl}$ electrode as the reference electrode, was used. Three electrodes were inserted into the quartz battery pack and the photocurrent was measured in $0.5 \mathrm{M} \mathrm{Na}_{2} \mathrm{SO}_{4}$ electrolyte. All the data were saved as a txt file format and redrawn/analyzed in Origin 8.5 or GraphPad Prism 9, and figure panels were integrated in Microsoft Office PowerPoint 2007. The chemical stability of the nanocatalyst in the pH7.4 PBS was investigated by SEM, UV, and inductively coupled plasma-atomic emission spectrometry (ICP-AES, Agilent Technologies, USA). After immersion in PBS $(30 \mu \mathrm{g} / \mathrm{mL}, 10 \mathrm{~mL})$ for fixed time periods $(0,3$, 7 days), the UV adsorption curve of the PBS solution of the nanocatalyst was measured, and nanoparticles were collected using the Millipore Ultra-Centrifugal Filter (molecular weight cut-off of 3000 Dalton) for TEM measurement, and the corresponding supernatant was used for ICP measurement $(n=3)$.

Detection of hydrogen production in vitro and in vivo. Hydrogen concentration was quantitatively monitored with a hydrogen microelectrode (Unisense, Denmark). In the simulated solution, the reaction solution of nanoplates $(100 \mu \mathrm{g} / \mathrm{mL})$ and GSH
$(10 \mu \mathrm{M})$ was gently stirred under protection of nitrogen, and separated with the detection solution by a piece of filter membrane (molecular weight cut-off of 3000 Dalton). The light spot of $808 \mathrm{~nm}$ laser completely covered the reaction solution rather than hydrogen microelectrode in the detection reaction solution once the beginning of hydrogen detection. The controllability of NIR-triggered hydrogen production was measured by repeatedly switching on/off the laser at fixed time points in the dark

In vitro, $4 \mathrm{~T} 1$ cells were incubated with nanoplates $(100 \mu \mathrm{g} / \mathrm{mL})$ for $12 \mathrm{~h}$, and then illustrated with $808 \mathrm{~nm}$ laser $\left(0.5 \mathrm{~W} / \mathrm{cm}^{2}\right)$ for $10 \mathrm{~min}$ in the dark, and finally lysed by rapid freeze-thaw twice. Immediately, the supernatant was collected by centrifugation, and used to detect hydrogen concentration with hydrogen electrode. In vivo, $4 \mathrm{~T} 1$ tumors of mice treated with nanoplates $(10 \mathrm{mg} / \mathrm{kg})$ for $4 \mathrm{~h}$ were illustrated with $808 \mathrm{~nm}$ laser $\left(0.5 \mathrm{~W} / \mathrm{cm}^{2}\right)$ for $20 \mathrm{~min}$ in the dark, then extracted and quickly lysed under the assistance of grinding. Immediately, the supernatant was collected by centrifugation for detection of hydrogen concentration with hydrogen electrode. Meanwhile, intracellular and intratumoral protein contents were detected by the BCA kit (Beyotime Biotech.) for calculation of relative hydrogen levels.

Detection of GSH depletion in vitro and in vivo. GSH concentration was quantitatively determined using the Ellmann probe (5,5'-dithiobis-(2-nitrobenzoic acid), DTNB). In the simulated solution, the natural light-sealed reaction solutions of nanoplates $(100 \mu \mathrm{g} / \mathrm{mL})$ and GSH $(10 \mu \mathrm{M})$ were irradiated with different power densities $\left(0,1,2 \mathrm{~W} / \mathrm{cm}^{2}\right)$ of $808 \mathrm{~nm}$ laser for different time periods (5-30 min). The nanoparticles in the solution were removed by centrifugation, and the supernatant of $20 \mu \mathrm{L}$ was added to the $10 \mathrm{~mL} 25 \mu \mathrm{M}$ DTNB solution and then diluted to $3 \mathrm{~mL}$ with $\mathrm{pH}=8.0$ phosphate buffer solution for UV measurement. The decrease of the absorbance at $412 \mathrm{~nm}$ was collected to calculate the concentration and consumption of GSH using the linear standard curve of DTNB solutions according to the Beer-Lambert law. Similar to hydrogen detection, lysed solutions of 4T1 cells and tumors which were respectively illustrated with $808 \mathrm{~nm}$ laser $\left(0.5 \mathrm{~W} / \mathrm{cm}^{2}\right)$ for $10 \mathrm{~min}$ and $20 \mathrm{~min}$ in the dark were collected for detection of in vitro and in vivo GSH depletion by the above Ellmann probe method.

Detection of intracellular and intratumoral levels of ATP and ROS. The intracellular and intratumoral levels of ATP and ROS were detected by ATP and ROS assay kits (Beyotime Biotech.), respectively. Similar to hydrogen and GSH detection, 4T1 cells and tumors were illustrated with $808 \mathrm{~nm}$ laser $\left(0.5 \mathrm{~W} / \mathrm{cm}^{2}\right)$ for $10 \mathrm{~min}$ and $20 \mathrm{~min}$, respectively. After $3 \mathrm{~h}, 4 \mathrm{~T} 1$ cells and tumors were lysed and the supernatant was immediately collected by centrifugation for detection of ATP and ROS levels in vitro and in vivo by corresponding assay kits.

Measurement of cellular uptake of nanoplates. The nanoplates were labeled with FITC-PEG-SH by the coordination method similar to the PTMP-PMAA modification. $4 \mathrm{~T} 1$ cells were seeded in a 6 -well plate containing slides at the density of $1 \times 10^{5}$ cells/well, and cultured with nanoplates at the final concentration of $100 \mu \mathrm{g} / \mathrm{mL}$ for $4 \mathrm{~h}$. The lysosomes and nuclei of $4 \mathrm{~T} 1$ cells were stained with LysoTracker Red and Hoechst (Beyotime Biotech.), respectively. After removal of excessive dyes, $4 \mathrm{~T} 1$ cells were observed on a confocal laser scanning microscope (ZEISS LSM880).

Intracellular DNA and mitochondrial damage measurement. 4T1 cells were cultured in a nanoplates-containing medium $(100 \mu \mathrm{g} / \mathrm{mL})$ for $12 \mathrm{~h}$, and then irradiated with $0.5 \mathrm{~W} / \mathrm{cm}^{2} 808 \mathrm{~nm}$ laser for $10 \mathrm{~min}$. After incubation for another $3 \mathrm{~h}, 4 \mathrm{~T} 1$ cells were stained with MitoTracker ${ }^{\oplus}$ Red CMXRos (Beyotime Biotech.) After incubation for another $20 \mathrm{~min}$, excessive dyes were removed by washing with fresh medium, and then $4 \mathrm{~T} 1$ cells were observed on a confocal laser scanning microscope (ZEISS LSM880) and meanwhile red fluorescence intensity per cell was calculated with ImageJ software to determine the intracellular mitochondrial amount. On the other hand, nanoplates-treated cells were digested by trypsin and washed with PBS, and then intracellular DNA damage was detected by comet assay ${ }^{50}$

In vitro cytotoxicity assessment. $4 \mathrm{~T} 1$ and HeLa cells were seeded into in 96-well cell culture plates at the density of $1 \times 10^{4} \mathrm{cells} / \mathrm{well}$, and incubated with various concentrations of nanoplates for $12 \mathrm{~h}$ at $37^{\circ} \mathrm{C}$ in a humidified $5 \% \mathrm{CO}_{2}$ atmosphere Cells were illustrated with 0.2 or $0.5 \mathrm{~W} / \mathrm{cm}^{2} 808 \mathrm{~nm}$ laser for $10 \mathrm{~min}$. After incubation for another $24 \mathrm{~h}$, the standard CCK-8 assay was executed to determine cell viability by collecting the absorbance at $450 \mathrm{~nm}$ on a microplate reader (BioTek). For proof of concept, UV ( $405 \mathrm{~nm}$ ) irradiation was used instead of NIR irradiation for photocatalytic generation of holes and hydrogen molecules. The cytotoxicities of two sacrificial agents, $\mathrm{AA}$ and $\mathrm{Na}_{2} \mathrm{~S}_{4} \mathrm{O}_{6}$, at different concentrations (31.2$4000 \mu \mathrm{M}$ ) were evaluated, and $250 \mu \mathrm{M}$ of concentration without visible cytotoxicity demonstration (Supplementary Fig. 9a) was chose for individual hole or hydrogen therapy (Supplementary Fig. 9b).

In vivo tumor-targeted delivery and biodistribution measurement. All the in vivo experiments followed the protocols which were approved by the Animal 
Care and Use Committee of Shenzhen University. The 4T1 tumor-bearing mice model was established by injecting $10^{7} 4 \mathrm{~T} 1$ cells into the hind limb of each female $\mathrm{BALB} / \mathrm{c}$ mouse (about $20 \mathrm{~g}$, purchased from Guangdong Medical Laboratory Animal Center). After tumors reached about $100 \mathrm{~mm}^{3}, 100 \mu \mathrm{L}$ PBS solution $(10 \mathrm{mg} / \mathrm{kg})$ of nanoplates was intravenously injected into $4 \mathrm{~T} 1$ tumor-bearing mice. Main organs (heart, liver, spleen, lung, kidney, and blood) and tumors were extracted at fixed time points $(1,2,4,12$, and $24 \mathrm{~h})$ post injection. These organs were weighted and then completely digested with aqua regia, heated to dryness and finally diluted with deionized water. The quantitative analysis of $\mathrm{Sn}$ was determined by ICP-AES to measure the biodistribution of nanoplates $(n=3)$.

In vivo tumor therapy assessment. For 4T1 tumor therapy, when tumor size reached approximately $80 \mathrm{~mm}^{3}$ (designed as day 0 ), the treatment was performed. Two experienced researchers randomly divided mice into six groups $(n=5)$, which were intravenously injected with $100 \mu \mathrm{L}$ PBS containing or excluding $\mathrm{SnS}_{2} /$ $\mathrm{SnS}_{1.68}-\mathrm{WO}_{2.41}$ nanoplates $(10 \mathrm{mg} / \mathrm{kg})$ followed with/without $808 \mathrm{~nm}$ laser irradiation $\left(0.5 \mathrm{~W} / \mathrm{cm}^{2}, 20 \mathrm{~min}\right) .20 \mathrm{~min} 808 \mathrm{~nm}$ laser irradiation upon tumors was executed at day 1 and day 3 . Body weight and tumor size of each mouse were recorded every other day. After 22 days of treatment, the tumors in the blank control group reached about $2000 \mathrm{~mm}^{3}$, and therefore all the mice were humanely executed. Main organs (heart, liver, spleen, lung, and kidney) and tumors were extracted for histological analysis by the hematoxylin and eosin (H\&E) staining method. For HeLa tumor therapy, the HeLa tumor-bearing mice model was established by injecting $1 \times 10^{7} \mathrm{HeLa}$ cells into the hind limb of each female BALB/ $\mathrm{c}$ nude mouse (about $15 \mathrm{~g}$, purchased from Guangdong Medical Laboratory Animal Center). When tumor size reached approximate $60 \mathrm{~mm}^{3}$ (designed as day 0 ), the treatment was performed, which was similar to the case of $4 \mathrm{~T} 1$ tumor therapy.

Assessment of liver/kidney functions and hemotoxicity. Health $\mathrm{BALB} / \mathrm{c}$ mice were randomly divided into 3 groups $(n=7)$ to be intravenously injected with $100 \mu \mathrm{L}$ PBS (as control), $100 \mu \mathrm{L} 100 \mathrm{mg} / \mathrm{kg} \mathrm{SnS}_{2}$ nanoplates, and $100 \mu \mathrm{L} 100 \mathrm{mg} / \mathrm{kg}$ $\mathrm{SnS}_{1.68}-\mathrm{WO}_{2.41}$ nanoplates, respectively. After 2 weeks, the blood was collected and assessed using a biochemical analyzer (iMagic-M7) and a blood cell analyzer (BC-31s, Mindray).

Reporting summary. Further information on research design is available in the Nature Research Reporting Summary linked to this article.

\section{Data availability}

All the data supporting the findings of this study are available within the article and its Supplementary information files and from the corresponding author upon reasonable request.

Received: 1 June 2020; Accepted: 1 February 2021;

Published online: 01 March 2021

\section{References}

1. Chow, E. K.-H. \& Ho, D. Cancer nanomedicine: from drug delivery to imaging. Sci. Transl. Med. 5, 216rv4 (2013).

2. Meng, J. et al. A multistage assembly/disassembly strategy for tumor-targeted CO delivery. Sci. Adv. 6, eaba1362 (2020).

3. Wang, Y., Yang, T. \& He, Q. Strategies for engineering advanced nanomedicines for gas therapy of cancer. Natl Sci. Rev. 7, 1485 (2020).

4. Li, S. et al. A DNA nanorobot functions as a cancer therapeutic in response to a molecular trigger in vivo. Nat. Biotechnol. 36, 258-264 (2018).

5. Zhao, R. et al. A drug-free tumor therapy strategy: cancer-cell-targeting. Angew. Chem. Int. Ed. 55, 5225-5229 (2016).

6. Huo, M., Wang, L., Chen, Y. \& Shi, J. Tumor-selective catalytic nanomedicine by nanocatalyst delivery. Nat. Commun. 8, 357 (2017).

7. Yang, B., Chen, Y. \& Shi, J. Nanocatalytic medicine. Adv. Mater. 31, 1901778 (2019).

8. Lin, H., Chen, Y. \& Shi, J. Nanoparticle-triggered in situ catalytic chemical reactions for tumour-specific therapy. Chem. Soc. Rev. 47, 1938-1958 (2018).

9. Fan, K. et al. In vivo guiding nitrogen-doped carbon nanozyme for tumor catalytic therapy. Nat. Commun. 9, 1440 (2018).

10. Fan, K. et al. Magnetoferritin nanoparticles for targeting and visualizing tumour tissues. Nat. Nanotechnol. 7, 459-464 (2012).

11. Zheng, D. W. et al. Optically-controlled bacterial metabolite for cancer therapy. Nat. Commun. 9, 1680 (2018).

12. Zheng, D. W. et al. Photocatalyzing $\mathrm{CO}_{2}$ to $\mathrm{CO}$ for enhanced cancer therapy. Adv. Mater. 29, 1703822 (2017).

13. Jian, J. X. et al. Chitosan confinement enhances hydrogen photogeneration from a mimic of the diiron subsite of [FeFe]-hydrogenase. Nat. Commun. 4 , 2695 (2013).
14. Voiry, D., Shin, H. S., Loh, K. P. \& Chhowalla, M. Low-dimensional catalysts for hydrogen evolution and $\mathrm{CO}_{2}$ reduction. Nat. Rev. Chem. 2, 0105 (2018).

15. Hisatomi, T. \& Domen, K. Reaction systems for solar hydrogen production via water splitting with particulate semiconductor photocatalysts. Nat. Catal. 2, 387-399 (2019)

16. Zhao, P. et al. Local generation of hydrogen for enhanced photothermal therapy. Nat. Commun. 9, 4241 (2018).

17. Wan, W. L. et al. Photosynthesis-inspired $\mathrm{H}_{2}$ generation using a chlorophyllloaded liposomal nanoplatform to detect and scavenge excess ROS. Nat. Commun. 11, 534 (2020).

18. Wan, W. L. et al. In situ nanoreactor for photosynthesizing $\mathrm{H}_{2}$ gas to mitigate oxidative stress in tissue inflammation. J. Am. Chem. Soc. 139, 12923-12926 (2017).

19. Zhang, B. et al. Polymer dots compartmentalized in liposomes as a photocatalyst for in situ hydrogen therapy. Angew. Chem. Int. Ed. 58, 2744-2748 (2019).

20. Yuan, Q. et al. Noble-Metal-Free Janus-like structures by cation exchange for $\mathrm{Z}$-scheme photocatalytic water splitting under broadband light irradiation. Angew. Chem. Int. Ed. 56, 4206 (2017).

21. Zhou, P., Yu, J. \& Jaroniec, M. All-Solid-State Z-scheme photocatalytic systems. Adv. Mater. 26, 4920-4935 (2014).

22. Wei, W. et al. Oxygen defect-induced localized surface plasmon resonance at the $\mathrm{WO}_{3-\mathrm{x}}$ quantum dot/silver nanowire interface: SERS and photocatalysis. Nanoscale 11, 5535-5547 (2019).

23. Manthiram, K. \& Alivisatos, A. P. Tunable localized surface plasmon resonances in tungsten oxide nanocrystals. J. Am. Chem. Soc. 134, 3995-3998 (2012).

24. Huang, W. et al. Oxygen vacancy induces self-doping effect and metalloid LSPR in non-stoichiometric tungsten suboxide synergistically contributing to the enhanced photoelectrocatalytic performance of $\mathrm{WO}_{3-\mathrm{x}} / \mathrm{TiO}_{2-\mathrm{x}}$ heterojunction. Phys. Chem. Chem. Phys. 20, 17268-17278 (2018).

25. Huang, X. Y. et al. Biolabeling hematopoietic system cells using near-infrared fluorescent gold nanoclusters. J. Phys. Chem. C. 115, 16753-16763 (2011).

26. Zhang, Z. et al. A nonmetal plasmonic Z-scheme photocatalyst with UV- to NIR-driven photocatalytic protons reduction. Adv. Mater. 29, 1606688 (2017).

27. $\mathrm{Lu}, \mathrm{N}$. et al. Direct evidence of IR-driven hot electron transfer in metal-free plasmonic $\mathrm{W}_{18} \mathrm{O}_{49}$ /carbon heterostructures for enhanced catalytic $\mathrm{H}_{2}$ production. Appl. Catal. B Environ. 233, 19-25 (2018).

28. Yan, J. et al. Tungsten oxide single crystal nanosheets for enhanced multichannel solar light harvesting. Adv. Mater. 27, 1580-1586 (2015).

29. Brongersma, M. L., Halas, N. J. \& Nordlander, P. Plasmon-induced hot carrier science and technology. Nat. Nanotechnol. 10, 25-34 (2015).

30. Wu, K. et al. Efficient hot-electron transfer by a plasmon-induced interfacial charge-transfer transition. Science 349, 632-635 (2015).

31. Mubeen, S. et al. Plasmonic photosensitization of a wide band gap semiconductor: Converting plasmons to charge carriers. Nano Lett. 11, 5548-5552 (2011).

32. Fan, $\mathrm{M}$. et al. Acid-responsive $\mathrm{H}_{2}$-releasing $2 \mathrm{D} \mathrm{MgB}_{2}$ nanosheet for therapeutic synergy and side effect attenuation of gastric cancer chemotherapy. Adv. Healthc. Mater. 8, 1900157 (2019).

33. Kou, Z. et al. Acid-responsive $\mathrm{H}_{2}$-releasing $\mathrm{Fe}$ nanoparticles for safe and effective cancer therapy. J. Mater. Chem. B 7, 2759-2765 (2019).

34. Liu, C. et al. Biodegradable biomimic copper/manganese silicate nanospheres for chemodynamic/photodynamic synergistic therapy with simultaneous glutathione depletion and hypoxia relief. ACS Nano 13, 4267-4277 (2019).

35. Ma, B. et al. Self-assembled copper-amino acid nanoparticles for in situ glutathione "AND" $\mathrm{H}_{2} \mathrm{O}_{2}$ sequentially triggered chemodynamic therapy. $J$. Am. Chem. Soc. 141, 849-857 (2019).

36. Gong, F. et al. Ultrasmall oxygen-deficient bimetallic oxide $\mathrm{MnWO}_{\mathrm{X}}$ nanoparticles for depletion of endogenous GSH and enhanced sonodynamic cancer therapy. Adv. Mater. 31, 1900730 (2019).

37. Yoo, D. et al. Glutathione-depleting pro-oxidant as a selective anticancer therapeutic agent. ACS Omega 4, 10070-10077 (2019).

38. Milanese, C. et al. DNA damage and transcription stress cause ATP-mediated redesign of metabolism and potentiation of anti-oxidant buffering. Nat. Commun. 10, 4887 (2019).

39. Chen, Y. et al. An immunostimulatory dual-functional nanocarrier that improves cancer immunochemotherapy. Nat. Commun. 7, 13443 (2016).

40. George, I. et al. Toxicological assessment of ITER-like tungsten nanoparticles using an in vitro 3D human airway epithelium model. Nanomaterials 9, 1374 (2019).

41. Tungsten, K. G. In Handbook on toxicology of metals. (eds Friberg, L., Norderg, G. F. \& Vouk, V.) 2nd edn, Vol II, 610-622 (Elsevier Science, 1986).

42. Chinde, $\mathrm{S}$. et al. Toxicological assessment of tungsten oxide nanoparticles in rats after acute oral exposure. Environ. Sci. Pollut. Res. 24, 13576 (2017).

43. Huo, D. et al. Eradication of unresectable liver metastasis through induction of tumour specific energy depletion. Nat. Commun. 10, 3051 (2019). 
44. Sheng, J. et al. Fabrication of dopamine enveloped $\mathrm{WO}_{3-\mathrm{x}}$ quantum dots as single-NIR laser activated photonic nanodrug for synergistic photothermal/ photodynamic therapy against cancer. Chem. Eng. J. 383, 123071 (2020).

45. Zhao, P. et al. PL-W ${ }_{18} \mathrm{O}_{49}$-TPZ nanoparticles for simultaneous hypoxiaactivated chemotherapy and photothermal therapy. ACS Appl. Mater. Interfaces 10, 3405 (2018).

46. Wen, L. et al. Ultrasmall biocompatible $\mathrm{WO}_{3-\mathrm{x}}$ nanodots for multi-modality imaging and combined therapy of cancers. Adv. Mater. 28, 5072 (2016).

47. Qiu, J. et al. Single $\mathrm{W}_{18} \mathrm{O}_{49}$ nanowires: A multifunctional nanoplatform for computed tomography imaging and photothermal/photodynamic/radiation synergistic cancer therapy. Nano Res. 8, 3580 (2015).

48. Chen, Z. et al. Ultrathin PEGylated $\mathrm{W}_{18} \mathrm{O}_{49}$ nanowires as a new $980 \mathrm{~nm}$-laserdriven photothermal agent for efficient ablation of cancer cells in vivo. $A d v$. Mater. 25, 2095 (2013).

49. Du, W. et al. Hexagonal tin disulfide nanoplatelets: a new photocatalyst driven by solar light. CrystEngComm 13, 2071-2076 (2011).

50. Speit, G. \& Rothfuss, A. The comet assay: a sensitive genotoxicity test for the detection of DNA damage and repair. Methods Mol. Biol. 920, 79 (2012).

\section{Acknowledgements}

We greatly appreciate the discussion with Prof. Xuejun Sun (SJTU, SMMU) and Prof Chenliang Su (SZU), the help of Dr. Shanshan Zhang (SIAT) in photoelectric measurement, and the Instrumental Analysis Center of Shenzhen University (XiLi campus) for assistance in material characterizations. Funding: This work was supported by the National Natural Science Foundation of China (51872188), Shenzhen Basic Research Program (JCYJ20170302151858466, JCYJ20170818093808351), Special Funds for the Development of Strategic Emerging Industries in Shenzhen (20180309154519685), SZU Top Ranking Project (860-00000210), and Center of Hydrogen Science, Shanghai Jiao Tong University, China.

\section{Author contributions}

Q.J.H. proposed the concepts and designed the project. B.Z. performed materials synthesis, physicochemical characterization, and biological experiments under assistance of Q.J.H., Z.K.J., Y.S.W., X.X.Y., and D.Y.C. M.J.F. did electrical microscopy measurement. Q.J.H. and B.Z. analyzed and interpreted the data, and wrote the manuscript.

\section{Competing interests}

The authors declare no competing interests.

\section{Additional information}

Supplementary information The online version contains supplementary material available at https://doi.org/10.1038/s41467-021-21618-1.

Correspondence and requests for materials should be addressed to Q.H.

Peer review information Nature Communications thanks the anonymous reviewers for their contribution to the peer review of this work.

Reprints and permission information is available at http://www.nature.com/reprints

Publisher's note Springer Nature remains neutral with regard to jurisdictional claims in published maps and institutional affiliations.

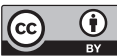

Open Access This article is licensed under a Creative Commons Attribution 4.0 International License, which permits use, sharing, adaptation, distribution and reproduction in any medium or format, as long as you give appropriate credit to the original author(s) and the source, provide a link to the Creative Commons license, and indicate if changes were made. The images or other third party material in this article are included in the article's Creative Commons license, unless indicated otherwise in a credit line to the material. If material is not included in the article's Creative Commons license and your intended use is not permitted by statutory regulation or exceeds the permitted use, you will need to obtain permission directly from the copyright holder. To view a copy of this license, visit http://creativecommons.org/ licenses/by/4.0/.

(C) The Author(s) 2021 